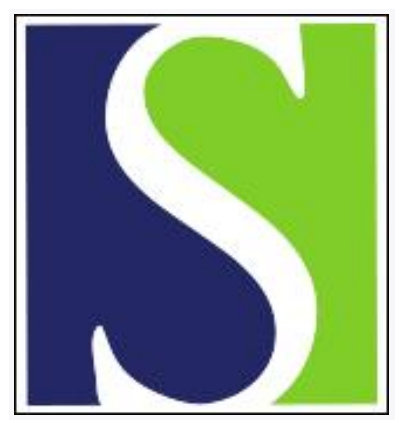

Scand J Work Environ Health 2006;32(4):318-327

https://doi.org/10.5271/sjweh.1016

Issue date: 31 Aug 2006

Overtime work and its effects on sleep, sleepiness, cortisol and blood pressure in an experimental field study

by Dahlgren A, Kecklund G, Åkerstedt T

Affiliation: National Institute for Psychosocial Medicine, PO Box 230, S-171 77 Stockholm, Sweden. anna.dahlgren@ipm.ki.se

Refers to the following texts of the Journal: 2003;29(4):261-269

1996;22(5):353-359 1996;22(2):124-132 2005;31(4):277-285

The following articles refer to this text: 2006;32(6):502-514;

2008;34(3):213-223; 2008;34(5):356-363; ; 2011;37(5):418-426;

2012;38(1):56-64; 2018;44(6):622-630

Key terms: blood pressure; cortisol; effect; experimental field study; fatigue; overtime work; sleep; sleepiness; stress; within-person design; workhours

This article in PubMed: www.ncbi.nlm.nih.gov/pubmed/16932830 


\title{
Overtime work and its effects on sleep, sleepiness, cortisol and blood pressure in an experimental field study
}

by Anna Dahlgren, ${ }^{1}$ Göran Kecklund, PhD, ${ }^{1}$ Torbjörn Åkerstedt, PhD ${ }^{1,2}$

\author{
Dahlgren A, Kecklund G, Åkerstedt T. Overtime work and its effects on sleep, sleepiness, cortisol and blood \\ pressure in an experimental field study. Scand J Work Environ Health 2006;32(4):318-327.
}

\begin{abstract}
Objectives Previous studies of long workhours and their effects on stress, sleep, and health show inconclusive results. This inconclusiveness may be partly due to methodological problems such as the use of between-group designs or comparisons before and after reorganizations. In addition, stress is usually a confounder. A withinperson design was used to examine the effects of working 8- or 12-hour shifts in the absence of additional stress. Methods In an experimental field study, 16 white-collar workers [9 women, mean age 45.9 (SD 15) years] undertook one workweek with normal workhours ( 8 hours) and 1 week of overtime with 4 extra hours of regular worktasks (12 hours). The participants wore actigraphs, rated sleepiness (Karolinska Sleepiness Scale) and stress throughout the day, and rated workload and how exhausted they felt. Saliva samples were collected on Mondays and Thursdays for cortisol analysis. On these days, ambulatory heart rate and blood pressure were also measured for 24 hours.

Results Overtime was associated with higher levels of exhaustion. Sleepiness showed a significant interaction between conditions, with higher levels at the end of the workweek featuring overtime. Total sleep time was shorter in the overtime week. There were no significant differences between ratings of stress and workload. Cortisol showed a circadian variation but no main effect of condition.

Conclusions One week of overtime work with a moderate workload produced no main effects on physiological stress markers. Nevertheless, sleep was negatively affected, with shorter sleeps during overtime work and greater problems with fatigue and sleepiness.
\end{abstract}

Key terms fatigue; stress; within-person design; workhours.

Long workhours (including overtime work) are prevalent within today's society. In the third European survey on work conditions, it was shown that $17 \%$ of fulltime employees work 45 hours or more a week (1). In Sweden about $30 \%$ of the working population works overtime every week, but the prevalence varies between occupational groups (1). In particular, white-collar workers form a group that frequently works overtime. For example, $70 \%$ of those with managerial positions work overtime every week, as do $45 \%$ of academics. Working long hours or overtime prolongs the exposure to work-related stressors, decreases time for leisure activities and family, and reduces time available for recuperation. Consequently, the potential risks of long hours may include an increase in stress-related illness, more disturbed sleep, greater daytime fatigue, and sleepiness and impaired performance.

Previous studies of long workhours have shown an association with increased stress $(2,3)$ and stress-related diseases such as elevated blood pressure and heart rate (4), myocardial infarctions $(5,6)$, and diabetes (7), as well as poor health behavior $(8,9)$. However, there are also studies that did not find any negative effects, and some studies have shown that certain groups with long workhours are at a decreased risk of suffering stress-related health problems $(10,11,12)$ and have less sickness absence (13).

Apart from studies concerning the prevalence of stress-related diseases, most previous studies of long workhours and stress have focused on the measurement

1 National Institute for Psychosocial Medicine, Stockholm, Sweden.

2 Department of Public Health Science, Karolinska Institutet, Stockholm, Sweden.

Reprint requests to: Anna Dahlgren, National Institute for Psychosocial Medicine, PO Box 230, S-171 77 Stockholm, Sweden. [E-Mail: anna.dahlgren@ipm.ki.se] 
of subjective ratings of stress, blood pressure, adrenaline, or norephepherine. Within stress research, the number of studies focusing on cortisol has increased in the past years, due to the possibility of measuring cortisol in saliva. In an acute stress situation, cortisol levels increase in healthy persons (14). However, within the research on long workhours, there are relatively few studies that have measured cortisol. In two studies that have examined the relationship between workhours and cortisol, the results showed no significant association $(15,16)$. However, none of the studies have examined the diurnal pattern of cortisol. Persson et al (15) measured cortisol in relation to a cognitive test between 0800 and 1100 in the morning, and in the study by Steptoe et al (16) it is not clear when the saliva samples were taken. It is therefore still not clear if or how long workhours affect cortisol levels.

Other effects of overtime work that have been demonstrated include sleep deprivation (17) (18), impaired performance (19), a higher injury hazard rate (20), and greater sleepiness and fatigue (21). But, once again, the findings are not consistent across studies, with other researchers having failed to find such effects (22).

In general, there are some methodological problems within the research on long workhours and overtime work that makes it hard to differentiate the effects of workhours per se from those caused by other factors. Numerous studies have used a cross-sectional design or have studied groups before and after reorganization. In many of these cases, it is hard to control for individual differences, as well as for the influence of different work characteristics. Furthermore, those who work much overtime are not only often in a work situation with high demands, but they also have high decision latitude and control, as well as high work motivation $(22,23)$. This situation makes comparisons between groups problematic since these job characteristics might work as buffering factors against the development of ill health. This possibility may explain the lack of negative effects in some studies of overtime work and health.

The few studies that have used a within-person design also suffer from methodological problems since they often compare periods with high and low overtime. In such cases, stress is often a confounder, since overtime work often coincides with a high workload. It is therefore hard to distinguish the effects of worktime from the effects of high workload and stress.

The diversity of results suggests that there are some work situations in which long workhours are not a problem with respect to health and safety, whereas, in other cases, they have adverse effects. While it is probable that workload and work-related stress are two of the most crucial factors moderating the impact of long hours, their precise role remains unclear.
In the present study we adopted an approach that was intended to avoid some of these methodological problems. We carried out an experimental field study, using a within-person design to compare two conditions in which worktime was manipulated while workload and stress were held constant, that is, there was no external pressure to increase workpace. Workhours were simply extended in time, and work was performed at a normal pace. The aim was to examine how overtime work affects sleep, fatigue, and physiological arousal. We also wanted to examine the effects on life outside of work and to identify which activities people would be most likely to cut down. One hypothesis was that overtime work would lead to higher physiological arousal, more disturbed and shorter sleep, and greater fatigue.

\section{Study population and methods}

\section{Study population and design}

This study involved 18 office workers who participated under two different conditions. One condition involved a workweek with 8-hour workdays throughout the week (40-hour workweek). In the other condition, the participants were asked to work overtime and extend their workdays with four extra hours per day [ie, work 12 hours per day (60 hours/week)]. During these extra 4 hours, the participants performed their normal worktasks. The aim was to keep workload and stress constant between conditions, and the participants were therefore asked to identify weeks that did not have any peaks in workload. The participants were also asked to keep the start of their workday constant in each condition. They could choose to recoup the overtime they worked in the form of free days or financial compensation.

One participant dropped out of the study, and two participants were excluded because of irregular working patterns. Of the remaining 15 participants, 9 were women, and the age span was from 27 to 65 years [mean age 45.9 (SD 15) years]. There were 4 participants that had children above the age of 7 years within the household, but no one had children under the age of 7 . The participants were recruited from several different worksites. Most (53\%) worked within academia (researchers, professors, research assistants), 20\% formed administrative staff (administrative supervisors, information personnel), and a computer consultant, an editor and a salesman made up the rest. The participants in this study had flexible worktime arrangements and could normally influence their own workhours. Their average workday was 9 hours and 11 minutes (SE 10 minutes). Once per month or more, $40 \%$ had a 50 -hour workweek, and $13 \%$ had a 60 -hour workweek. There was no difference 
in the number of workhours for the week before the two conditions $[\mathrm{t}=0.0, \mathrm{df}=9, \mathrm{P}>0.5 ; 8$ hours $=2.9$ (SE 0.5), 12 hours $=2.9$ (SE 0.3); scale $1(<37.5$ hours/week) to $6(>60$ hours/week].

The two conditions were counterbalanced, but, due to the three dropouts, seven started with the overtime week, and eight started with the 40-hour workweek. From Monday to Sunday the participants made ratings of stress, sleepiness, and mental fatigue in a diary at awakening, during the day and in the evening (at 0700 , 1000, 1300, 1600, 1900 and 2200) in both conditions. At the end of each day, the participants also reported how their day had been with respect to different symptoms of stress and cognitive performance. On the Monday and Thursday in each condition, they carried out additional measurements, such as saliva samples for cortisol and also ambulatory measurement of heart rate and blood pressure.

\section{Self ratings}

Ratings of stress were made at 0700, 1000, 1300, 1600, 1900 , and 2200 on a 9-point scale. The stress rating scale was inspired by the work of Kjellberg \& Iwanowski (24) and their development of the "stress-energy rating questionnaire". They used almost 100 mood adjectives that were factor analyzed. A series of factor analyses was carried out, and the final outcome was a two-factor structure. The factors were labeled "energy" (represented by adjectives like active, energetic, efficient, and the like) and "stress" (represented by adjectives like tense, stressed, under pressure, and the like). The dimensions included six items each. The "stressenergy scale" has been validated, with good results, against job-strain measures (25). However, since we needed to collect information about stress at several times of the day for 2 weeks, it would have been too much of a burden for the participants to complete the entire questionnaire. Therefore, the items of the stress dimension were integrated into a single rating scale. The scale included nine response categories, of which five included verbal anchors: 1 very low stress (very calm and relaxed), 3 low stress (calm and relaxed), 5 neither low or high stress, 7 high stress (high tension and pressure), 9 high stress (very high tension and pressure).

The participants also rated their sleepiness during the day in the diary using the Karolinska Sleepiness Scale (KSS): 1 = very alert-9 very sleepy, fighting sleep or effort to stay awake. The scale has been validated against physiological and behavioral measures (26). Electroencephalographic (EEG) and electrooculographic (EOG) changes characteristic of sleepiness usually begin to appear at a value of 7 (26). The scale for mental fatigue varied from 1 to 9 , of which 5 included verbal anchors: 1 = very active, very high energy, $3=$ high energy, $5=$ neither energetic or slow, $7=$ fatigue but not too hard to make a mental effort, $9=$ very slow, low energy, inactive. Scores on this scale have been shown to increase on early morning shifts, in a previous study on train drivers (27).

The questions at the end of the day concerned whether the participants had felt tense, exhausted, irritated, worn out, under time pressure, had had difficulties thinking ( $1=$ to a large extent, $5=$ not at all), and whether they had enough recuperation during the day $(1=$ definitely enough, 5 = far from enough). On a scale from 1 to 5 ( 1 = very low, 5 = very high $)$, the participants also answered questions about how they had perceived the workload, ("how was the workload"), workpace ("how was the workpace"), and also how satisfied they were with their own work performance $(1=$ very dissatisfied, 5 = very satisfied).

The participants were also asked to report what they did after work. They noted in the diary what kind of activity they had been involved in for the past $30 \mathrm{~min}$ utes. In order to make it easier to fill out the diary, activities were classified into different categories, such as "household work", "caring for children or relatives", "leisure activities", "rest or sleep", "spending time for yourself", "watching television", and the like.

Every morning during both weeks, the participants filled out the Karolinska Sleep Diary (KSD) (28). It consists of several questions concerning the previous night's sleep, such as feeling "fully rested" after sleep, "early awakening", and "ease of falling asleep". Ratings were made on a 5 -point scale $(1=$ poor sleep, $5=$ no problems with sleep). Two indices were formed using items from the diary. The first index was an overall measure of the quality of sleep and contained the items "restless sleep", "ease falling asleep", "sleep quality" (phrased as "how did you sleep") and "slept throughout". The second index reflected the ease of awakening and was formed using the items "ease awakening" and "fully rested".

\section{Actigraphy}

Throughout both conditions the participants wore an actigraph (Cambridge Neurotechnology Ltd, UK), which measured wrist activity. The participants were instructed to press an event button when going to sleep (lights out) and at awakening. For scoring the data, the Actiwatch Sleep Analysis program (version 1.09, Cambridge, UK) was used. The output sleep score has a high correspondence with polysomnographically recorded sleep for the parameter total sleep time (29). Of all the sleep recordings, about $14 \%$ were lost due to participants failing to wear the actigraph. The measures obtained were bedtime, wake-up time, actual sleep time (excluding time awake) and sleep efficiency (actual sleep time/total sleep time $\times 100$ ). 


\section{Cortisol}

On the Monday and the Thursday in each condition, the participants gave saliva samples using Salivette (Sarstedts, Rommelsdorf, Germany) cotton swabs. The participants kept a swab in his or her mouth for about 1 minute, put it in a test tube, and then sealed it. The samples were obtained 15 minutes after awakening, at 0800 , $1100,1400,1700,2000,2300$, and at bedtime. The participants were instructed to avoid food for 30 minutes before these time points. There were no differences in the sampling time between conditions at awakening or bedtime. About $8 \%$ of the samples were lost. When possible, missing data were replaced by a mean value based on adjacent values. Missing data at awakening and bedtime were not replaced because of the lack of adjacent values. Missing data at 8 hours were not replaced either, since using the preceding high morning value would probably have resulted in a mean value that was too high and misleading. The cortisol samples were analyzed by radioimmunoassay, using the Spectria ( ${ }^{125}$ I) coated-tubes radioimmunoassay kit (Orion Diagnostica, FI-02101 Espoo, Finland). The within-assay coefficient of variation ranged from 0.5 to 6 , and the between-assay coefficients never exceeded $10 \%$.

\section{Heart rate and blood pressure}

On Monday and Thursday in each condition, ambulatory blood pressure and heart rate were measured for 24 hours at 1-hour intervals during the day and at 2-hour intervals during the night, using an ambulatory blood pressure monitor (Spacelabs Medical Inc, Issaquah, WA, USA). About $14 \%$ of the day data (between 0800 and 2200) and about 19\% of the night data (between 2400 and 0700 ) were missing. A mean for the values at work, after work, and during sleep was calculated to reduce the effects of physical activity and to overcome the problem of missing data points.

\section{Statistical analyses}

A two-factor analysis of variance (ANOVA) for repeated measurements was used to detect differences in the diary ratings between conditions and any interaction during the workweek. The first factor was condition (8hour day or 12-hour day), and the second was workdays (Monday to Friday). In order to analyze any possible effects during the following weekend, we compared the means across the weekends in a paired t-test analysis.

The cortisol data were analyzed using a three-way ANOVA for repeated measures with weekday as the first factor, condition as the second factor, and time of day as the third factor. When the ANOVA showed a significant three-way interaction, data were further analyzed. In order to increase the number of participants in the analysis of morning values, we analyzed values during work (mean between 0800 and 1800) and evening (mean 2300 and bedtime) separately using a two-way ANOVA with condition as the first factor and weekday as the second factor.

The heart rate and blood pressure data were averaged for values taken at work, after work, and during sleep. The resulting means were analyzed in a two-way ANOVA for repeated measurements with condition as the first factor and weekday as the second factor.

Correction for sphericity, using the Huyhn-Feldt procedure, was performed when necessary, and only the adjusted F-values are presented in this paper. The alpha level was set to 0.05 in all of the analyses.

\section{Results}

The symptoms of health, stress, and sleepiness are shown in table 1 . The participants reported feeling more exhausted, having more difficulties thinking, being more irritated, and having less sufficient recuperation during the overtime week. Sleepiness showed a significant interaction with more or stronger symptoms at the end of the week, as demonstrated in figure 1. The analysis of the diurnal variation in sleepiness during Friday is presented in figure 1 and shows significantly greater sleepiness throughout the day in the overtime week $(\mathrm{F}(1,11)=35.2, \mathrm{P}<0.001)$, as well as a significant effect of time of day $(\mathrm{F}(6,66)=6.2, \mathrm{P}<0.001)$. There were no differences in mental fatigue, stress, time pressure, or feeling tense. The results from questions concerning health and health-related behavior did not show any differences in the health status or alcohol consumption. However, during the overtime week, the participants drank significantly more coffee.

Table 1 shows the worktimes for each week. The participants had an earlier start of their workday during the overtime week and varied the start during the workweek with an earlier start on Friday. The results showed no differences in perceived workload, workpace, or satisfaction with work performance and therefore indicated that the work situation was fairly similar during both conditions.

The ratings of time spent on different activities after work showed that the participants spent significantly less time on household work, time for themselves, and time socializing with other people during the overtime week.

The results from the participants' ratings of sleep and data from the actigraph measures are shown in table 1 . There were no significant differences between the conditions in the subjective ratings of sleep quality, 
Table 1. Results of a two-way analysis of variance for repeated measures on data from the diaries and actigraphy. (SE = standard error, $\mathrm{df}=$ degrees of freedom, * alpha $\mathrm{P}<0.05,{ }^{* *}$ alpha $\mathrm{P}<0.01,{ }^{* * *}$ alpha $\left.\mathrm{P}<0.001\right)$

\begin{tabular}{|c|c|c|c|c|c|c|c|c|c|c|}
\hline & \multicolumn{2}{|c|}{ 12-hour workday } & \multicolumn{2}{|c|}{ 8-hour workday } & \multicolumn{6}{|c|}{ F-value } \\
\hline & Mean & SE & Mean & SE & $\begin{array}{l}\text { Condi- } \\
\text { tion }\end{array}$ & $\begin{array}{l}\text { df } 1 \\
\text { for con- } \\
\text { dition }\end{array}$ & $\begin{array}{l}\text { Monday } \\
\text { through } \\
\text { Friday }\end{array}$ & $\begin{array}{c}\text { df } 4 \text { for } \\
\text { Monday } \\
\text { through } \\
\text { Friday }\end{array}$ & $\begin{array}{l}\text { Inter- } \\
\text { action }\end{array}$ & $\begin{array}{l}\text { df } 4 \\
\text { for } \\
\text { inter- } \\
\text { action }\end{array}$ \\
\hline \multicolumn{11}{|l|}{ Diary ratings of work } \\
\hline Started work & 0756 & 0009 & 0824 & 0014 & $12.8^{\star *}$ & 12 & $5.6^{\star \star}$ & 48 & 0.8 & 48 \\
\hline Finished work & 1959 & 0015 & 1657 & 0013 & $99.7^{\star \star *}$ & 12 & 2.6 & 48 & 0.3 & 48 \\
\hline Total workhours (hours:minutes) & $12: 04$ & $0: 08$ & $8: 35$ & $0: 09$ & $274.3^{\star * *}$ & * 11 & .8 & 44 & 0.2 & 44 \\
\hline Workload ( $1=$ =ery low, $5=$ very high) & 3.5 & 0.2 & 3.3 & 0.2 & 1.2 & 10 & 0.68 & 40 & 0.3 & 40 \\
\hline Workpace ( $1=$ very low, $5=$ very high) & 3.3 & 0.2 & 3.2 & 0.2 & 0.1 & 10 & 0.8 & 40 & 1.0 & 40 \\
\hline $\begin{array}{l}\text { Satisfied with work (1=very dissatisfied, } \\
5=\text { very satisfied) }\end{array}$ & 3.6 & 0.2 & 3.5 & 0.2 & 0.8 & 11 & $3.4^{\star}$ & 44 & 1.6 & 44 \\
\hline \multicolumn{11}{|l|}{ Diary ratings of health, stress and fatigue } \\
\hline $\begin{array}{l}\text { Sleepiness- KSS (1=very alert, } \\
9=\text { very sleepy) }\end{array}$ & 3.9 & 0.2 & 3.9 & 0.2 & 0.1 & 12 & 0.8 & 48 & $4.2^{*}$ & 48 \\
\hline Stress $(1=$ low stress, $9=$ very high stress) & 3.1 & 0.2 & 3.1 & 0.2 & 0.0 & 12 & 1.2 & 48 & 1.8 & 48 \\
\hline Mental fatigue ( $1=$ very active, $9=$ =ery slow) & 4.0 & 0.2 & 3.9 & 0.2 & 1.4 & 11 & 0.7 & 44 & 1.0 & 44 \\
\hline Worn out ( $1=$ difficulties, $5=$ no problems) & 4.7 & 0.2 & 5 & 0.0 & $15.7^{* *}$ & 11 & 1.8 & 44 & 2.3 & 44 \\
\hline Irritated $(1=$ difficulties, $5=$ no problems $)$ & 4.5 & 0.1 & 4.7 & 0.1 & $5.4^{\star}$ & 11 & 1.1 & 44 & 0.4 & 44 \\
\hline Exhausted $(1=$ difficulties, $5=$ no problems $)$ & 4.8 & 0.1 & 5 & 0.0 & $6.1^{*}$ & 11 & 0.7 & 44 & 2.3 & 44 \\
\hline $\begin{array}{l}\text { Difficulties thinking }(1=\text { difficulties, } \\
5=\text { no problems })\end{array}$ & 4.6 & 0.1 & 4.9 & 0.1 & $7.0^{*}$ & 11 & 2.0 & 44 & 1.1 & 44 \\
\hline $\begin{array}{l}\text { Sufficient recuperation ( } 1=\text { not sufficient, } \\
5=\text { sufficient) }\end{array}$ & 3.3 & 0.1 & 3.8 & 0.2 & $9.4^{*}$ & 11 & 0.5 & 44 & 0.3 & 44 \\
\hline $\begin{array}{l}\text { Time pressure }(1=\text { difficulties, } \\
5=\text { no problems })\end{array}$ & 4.4 & 0.1 & 4.4 & 0.1 & 0.8 & 11 & 1.0 & 44 & 1.0 & 44 \\
\hline Tense $(1=$ difficulties, $5=$ no problems $)$ & 4.4 & 0.2 & 4.5 & 0.2 & 0.8 & 11 & 0.5 & 44 & 0.5 & 44 \\
\hline Overall health $(1=$ very poor, $5=$ excellent $)$ & 5.9 & 0.2 & 5.8 & 0.3 & 0.5 & 11 & 1.0 & 44 & 2.5 & 44 \\
\hline $\begin{array}{l}\text { Pain symptoms }(1=\text { difficulties, } \\
5=\text { no problems })\end{array}$ & 4.5 & 0.2 & 4.6 & 0.2 & 2.2 & 10 & 0.7 & 40 & 0.7 & 40 \\
\hline $\begin{array}{l}\text { Alcohol (Monday to Thursday; } 0=\text { none, } \\
3=\text { a lot, party consumption) }\end{array}$ & 0.2 & 0.0 & 0.4 & 0.1 & 4.3 & 13 & 0.5 & 39 & 0.3 & 39 \\
\hline Coffee (no) & 3.0 & 0.3 & 2.7 & 0.2 & $5.6^{*}$ & 8 & 1.3 & 32 & 1.1 & 32 \\
\hline \multicolumn{11}{|l|}{ Ratings of activities after work } \\
\hline Household work (hours:minutes) & $0: 40$ & $0: 04$ & 1:01 & $0: 07$ & $9.9^{* *}$ & 14 & 1.3 & 56 & 1.7 & 56 \\
\hline Leisure time (hours:minutes) & $1: 15$ & $0: 12$ & $1: 24$ & $0: 14$ & 3.7 & 14 & 2.6 & 56 & 1.0 & 56 \\
\hline Time for one's self (hours:minutes) & $1: 01$ & $0: 14$ & $1: 38$ & $0: 11$ & $5.8^{*}$ & 14 & 0.9 & 56 & 0.9 & 56 \\
\hline Watching TV (hours:minutes) & $1: 30$ & $0: 14$ & $1: 33$ & $0: 11$ & 1.7 & 14 & 1.2 & 56 & 1.8 & 56 \\
\hline Rest and relaxation (hours:minutes) & $0: 57$ & $0: 19$ & $0: 39$ & $0: 04$ & 0.0 & 14 & 0.7 & 56 & 0.2 & 56 \\
\hline Socialize (hours:minutes) & 2:01 & $0: 24$ & $2: 39$ & $0: 24$ & $19.0^{* * *}$ & 14 & 2.9 & 56 & 0.7 & 56 \\
\hline \multicolumn{11}{|l|}{ Diary ratings of sleep } \\
\hline Bedtime & 2309 & 0012 & 2320 & 0009 & 2.9 & 12 & 0.1 & 48 & 1.7 & 48 \\
\hline Wake-up time & 0610 & 0015 & 0620 & 0015 & 1.2 & 10 & 2.2 & 40 & 0.4 & 40 \\
\hline Time in bed (hours:minutes) & $6: 54$ & $0: 06$ & $6: 55$ & $0: 08$ & 0.0 & 10 & 1.6 & 40 & 1.3 & 40 \\
\hline $\begin{array}{l}\text { Stress or restlessness at bedtime } \\
\text { ( } 1=\text { difficulties, } 5=\text { no problems) }\end{array}$ & 4.5 & 0.2 & 4.5 & 0.1 & 0.0 & 13 & 1.8 & 52 & 0.1 & 52 \\
\hline $\begin{array}{l}\text { Sleep quality index ( } 1 \text { = difficulties, } \\
5=\text { no problems) }\end{array}$ & 4.0 & 0.2 & 4.1 & 0.2 & 0.4 & 13 & 2.0 & 52 & 1.7 & 52 \\
\hline $\begin{array}{l}\text { Awakening index }(1=\text { difficulties, } \\
5=\text { no problems })\end{array}$ & 2.9 & 0.1 & 3.1 & 0.2 & 1.9 & 13 & 0.5 & 52 & 0.0 & 52 \\
\hline \multicolumn{11}{|l|}{ Actigraphy } \\
\hline Sleep start & 2332 & 0015 & 2337 & 0015 & 0.9 & 9 & 0.0 & 36 & 0.9 & 36 \\
\hline Sleep end & 0629 & 0013 & 0651 & 0016 & $5.4^{*}$ & 9 & 36 & 36 & $3.4^{\star}$ & 36 \\
\hline Assumed sleep (hours:minutes) & $6: 58$ & $0: 07$ & $7: 14$ & $0: 08$ & $14.7^{\star \star}$ & 9 & 0.6 & 36 & 0.4 & 36 \\
\hline Total sleep time (hours:minutes) & $6: 24$ & $0: 08$ & $6: 42$ & $0: 08$ & $10.6^{* \star}$ & 9 & 0.6 & 36 & 0.4 & 36 \\
\hline Sleep efficiency $(\%)$ & 92.0 & 1.1 & 92.6 & 2.6 & 1.5 & 9 & 1.2 & 36 & 1.8 & 36 \\
\hline
\end{tabular}

awakening problems, stress or restlessness at bedtime, or the objective measures of sleep efficiency. There was good consistency between the participants' subjective reports of bedtimes and the actigraphy measures. There were no differences in the subjective measures; howev- er, the actigraphy data showed significant differences for the wake-up time and the actual sleep time. During the overtime week, the participants had a shorter total sleep time and woke up earlier. They also showed a significant interaction for wake-up times; in the overtime 


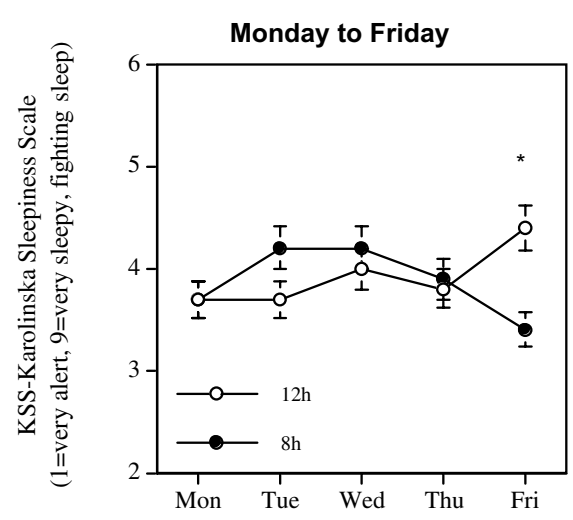

Monday

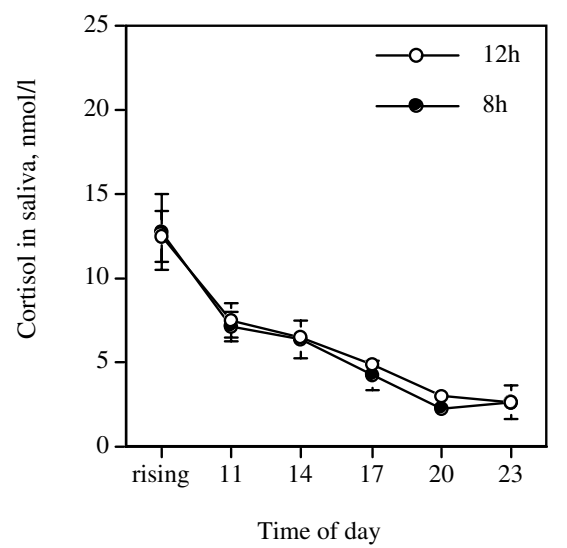

Friday

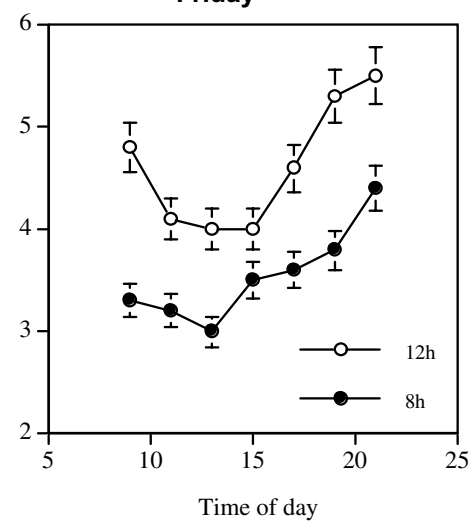

Figure 1. Means and standard errors of the means for sleepiness from Monday to Friday during each condition and for sleepiness throughout Friday in each condition (right). ( ${ }^{*} \mathrm{P}<0.05$ with pairwise t-test)
Figure 2. Means and standard errors of the means for the cortisol level during Monday (left) and Thursday (right) in each condition. Cortisol at rising was taken 15 minutes after the participant awakened. condition, the wake-up time was earlier by the end of the week.

In order to examine the relationship between the earlier wake-up time and symptoms of stress and fatigue, we performed a set of correlation analyses using the difference in the mean values between the two measurement weeks. The results showed no significant correlations between the wake-up time and "sufficient recuperation" ( $\mathrm{r}=0.13, \mathrm{P}>0.05)$, "exhaustion" ( $\mathrm{r}=-0.34$, $\mathrm{P}>0.05)$, "worn out" ( $\mathrm{r}=-0.51, \mathrm{P}>0.05)$, "irritation" ( $\mathrm{r}=-$ $0.08, \mathrm{P}>0.05)$ and "difficulties thinking" ( $\mathrm{r}=-0.48$, $\mathrm{P}>0.05)$. However there was a significant correlation between the wake-up times and start of the workday $(\mathrm{r}=0.59, \mathrm{P}<0.05)$.

The cortisol data are presented in figure 2 . The threeway ANOVA for repeated measurements showed no difference between the conditions $(F(1,8)=0.3, P>0.05)$, but there was a significant effect of time of day $(\mathrm{F}(5,40)=26.6, \mathrm{P}<0.001)$ and a significant two-way interaction between condition and time of day $(\mathrm{F}(5,40)=3.2, \mathrm{P}<0.05)$. However, the interaction effect was rather weak, and, as demonstrated in table 2, additional analyses of the morning values, values at work, and values after work showed no significant differences between the conditions. However, the analysis of the morning values showed a trend towards an interaction effect $(\mathrm{P}<0.10)$, higher morning values being observed on Thursday of the overtime week. There were no significant differences in the sampling times of the first morning measures. The morning values and wake-up times showed no significant correlation.

The heart rate and blood pressure data are presented in table 2. The systolic and diastolic blood pressure did not show any effects on condition or weekday during work, after work, or during sleep. However, there were significant interactions during work with respect to systolic blood pressure, and, during the week with overtime, the participants showed a lower systolic pressure from Monday to Thursday. For the 8-hour condition, the opposite pattern was apparent. The heart rate data did not show any significant effects with respect to condition, but there was a significant effect with respect to weekday for the night measures and a significant interaction between condition and weekday for the measures after work. The heart rate during sleep increased from Monday to Thursday. The measurements after work showed a decrease from Monday to Thursday during the overtime week, whereas an increase occurred from Monday to Thursday during the 8-hour workweek. 
Table 2. Results from a threeway analysis of variance for repeated measures with data from the cortisol samples and the ambulatory heart rate and blood pressure measurement during Monday and Thursday of each condition. (df = degrees of freedom, SE $=$ standard error of the mean)

\begin{tabular}{|c|c|c|c|c|c|c|c|c|c|c|c|c|}
\hline & \multicolumn{4}{|c|}{ Overtime } & \multicolumn{4}{|c|}{ 8-hour workday } & \multicolumn{3}{|c|}{ F-value } & \multirow[t]{3}{*}{ df $1^{a}$} \\
\hline & \multicolumn{2}{|c|}{ Monday } & \multicolumn{2}{|c|}{ Thursday } & \multicolumn{2}{|c|}{ Monday } & \multicolumn{2}{|c|}{ Thursday } & \multirow[t]{2}{*}{ Condition } & \multirow{2}{*}{$\begin{array}{l}\text { Monday- } \\
\text { Friday }\end{array}$} & \multirow{2}{*}{$\begin{array}{l}\text { Inter- } \\
\text { action }\end{array}$} & \\
\hline & Mean & SE & Mean & SE & Mean & SE & Mean & SE & & & & \\
\hline \multicolumn{13}{|c|}{ Cortisol in saliva (nmol/l) } \\
\hline Morning & 11.6 & 1.5 & 15.0 & 2.8 & 13.5 & 1.7 & 10.5 & 1.4 & 0.5 & 0.0 & 3.2 & 12 \\
\hline At work & 6.7 & 0.5 & 7.2 & 0.7 & 6.7 & 0.7 & 6.4 & 0.5 & 0.5 & 0.1 & 0.7 & 13 \\
\hline After work & 2.7 & 0.4 & 1.9 & 0.4 & 3.3 & 1.3 & 2.1 & 0.4 & 0.3 & 3.1 & 0.1 & 11 \\
\hline \multicolumn{13}{|c|}{ Blood pressure and heart rate } \\
\hline \multicolumn{13}{|l|}{ At work } \\
\hline Systolic & 126.2 & 5.2 & 123.0 & 4.2 & 123.4 & 4.8 & 126.6 & 4.5 & 0.1 & 0.0 & $10.4^{\star \star}$ & 13 \\
\hline Diastolic & 78.8 & 1.3 & 78.4 & 1.1 & 78.2 & 1.5 & 79.0 & 1.5 & 0.0 & 0.1 & 0.7 & 13 \\
\hline Heart rate & 66.8 & 1.9 & 69.9 & 2.2 & 69.1 & 2.4 & 67.8 & 1.4 & 0.0 & 0.4 & 2.4 & 13 \\
\hline \multicolumn{13}{|l|}{ After work } \\
\hline Systolic & 123.1 & 4.8 & 122.7 & 3.8 & 123.5 & 4.7 & 123.0 & 5.1 & 0.0 & 0.1 & 0.0 & 12 \\
\hline Diastolic & 75.6 & 1.8 & 75.1 & 1.8 & 75.0 & 1.6 & 76.1 & 2.2 & 0.0 & 0.1 & 0.7 & 12 \\
\hline Heart rate & 68.8 & 2.4 & 67.0 & 2.2 & 66.1 & 1.5 & 70.9 & 2.1 & 0.1 & 1.0 & $5.5^{*}$ & 12 \\
\hline \multicolumn{13}{|l|}{ During sleep } \\
\hline Systolic & 102.0 & 5.1 & 101.2 & 4.1 & 98.8 & 4.1 & 102.8 & 5.1 & 0.6 & 1.6 & 2.2 & 11 \\
\hline Diastolic & 61.1 & 2.1 & 62.0 & 2.0 & 60.7 & 2.3 & 60.4 & 2.3 & 0.6 & 0.1 & 0.4 & 11 \\
\hline Heart rate & 57.9 & 2.1 & 58.6 & 2.2 & 57.6 & 2.1 & 60.7 & 2.2 & 0.5 & $6.2^{*}$ & 0.7 & 11 \\
\hline
\end{tabular}

a Same within each analysis for all of the F-values.

Table 3. Results of the paired t-test for data from the diary and actigraphy during the weekends. $(\mathrm{df}=$ degrees of freedom, $\mathrm{SE}=$ standard error of the mean)

\begin{tabular}{|c|c|c|c|c|c|c|}
\hline & \multicolumn{2}{|c|}{ Overtime } & \multicolumn{2}{|c|}{ 8-hour workday } & \multirow{2}{*}{$\begin{array}{c}\mathrm{t}- \\
\text {-Value }\end{array}$} & \multirow[t]{2}{*}{ df } \\
\hline & Mean & SE & Mean & SE & & \\
\hline \multicolumn{7}{|l|}{ Diary ratings of sleep } \\
\hline Bedtime & 2437 & 0023 & 2427 & 0025 & 0.5 & 12 \\
\hline Wake-up time & 0819 & 0029 & 0823 & 0030 & -0.4 & 12 \\
\hline Time in bed (hours:minutes) & $7: 42$ & $0: 14$ & $7: 56$ & $0: 14$ & -0.7 & 12 \\
\hline $\begin{array}{l}\text { Stress or restlessness } \\
\text { at bedtime }{ }^{\text {a }}\end{array}$ & 4.7 & 0.1 & 4.8 & 0.1 & -0.7 & 12 \\
\hline Sleep quality index ${ }^{a}$ & 4.4 & 0.2 & 4.3 & 0.1 & 1.2 & 12 \\
\hline Awakening index ${ }^{a}$ & 3.8 & 0.3 & 3.5 & 0.1 & 1.5 & 12 \\
\hline \multicolumn{7}{|l|}{ Actigraphy } \\
\hline Sleep start & 2459 & 0019 & 0108 & 0021 & -0.6 & 9 \\
\hline Sleep end & 0905 & 0026 & 0925 & 0030 & -1.1 & 9 \\
\hline $\begin{array}{l}\text { Assumed sleep } \\
\text { (hours:minutes) }\end{array}$ & 8:06 & $0: 18$ & $8: 18$ & $0: 17$ & -0.5 & 9 \\
\hline $\begin{array}{l}\text { Total sleep time } \\
\text { (hours:minutes) }\end{array}$ & $7: 31$ & $0: 17$ & $7: 31$ & $0: 13$ & 0.01 & 9 \\
\hline Sleep efficiency (\%) & 93.0 & 0.8 & 90.8 & 1.3 & $2.6^{*}$ & 9 \\
\hline
\end{tabular}

a 1 = difficulties, $5=$ no difficulties

Table 3 shows the analysis of data from the weekend at the end of the measurement week. Due to indistinct instructions about which ratings to make during the weekend, we have missing data from some parts of the diary. Data from these parts of the diary are therefore not presented in this paper. However, from the remaining data, virtually none of the variables showed a significant difference between the conditions, except for sleep efficiency. Sleep efficiency was higher during the weekend after the overtime week.

\section{Discussion}

This is the first study in which the perceived workload and workpace were held constant when the effects of overtime work were examined with a within-person design. The results indicated that a week with overtime work was associated with decreased sleep, more symptoms of fatigue, and an increase in sleepiness at the end of the week. These findings agree with some results from previous studies $(3,17,18)$. However, we could not determine whether the increase in fatigue and sleepiness was due to the workhours per se or if it was an effect of the shorter sleep time. The suggestion that overtime reduces sleep time is supported by results from other studies, which have shown an association between long workhours and sleep deprivation $(6,17)$, leading to increased symptoms of fatigue.

Reduced sleep during the overtime week may have been a result of the participants waking earlier even if the phase advance was only 28 minutes. However, it may have contributed to some extent. Moreover, there were no significant correlations between how much earlier the participants awoke in the overtime week and concomitant changes in fatigue. The reason for the earlier awakening may have been anticipation of a forthcoming 
difficult day. It may also have been a conscious decision despite instructions to maintain normal sleep hours.

With regard to sleep, it has been argued that it might be one of the key factors in the development of stressrelated diseases in connection with overtime work (6). It seems likely that there is a two-way relationship between sleep and stress. Specifically, short sleep will lead to an elevation in markers of stress (30), while stress in itself appears to have negative effects on sleep (31). In the present study there was an association between overtime work and sleep length, but there was no clear relation between overtime work and any of the physiological stress markers. On the other hand, only one week with overtime work was scheduled, and it may be that a longer period would lead to an accumulation of sleep debt and sleep problems with a subsequent alteration in the physiological measures.

The cortisol data did not show any significant main effect for overtime. However, the interaction effect from the three-way ANOVA and the trend towards an interaction effect in the analysis of the morning values suggest that the overtime week was associated with an increase in the morning value at the end of the week, on Thursday. This finding may indicate that working overtime induced higher arousal, and this finding is supported by previous research that has found an association between high arousal and high morning cortisol (32). However, since the effect is rather weak, these data should be interpreted with caution. The reasons for the rather weak effect could possibly be that there are individual variations in the cortisol response, such that some people react with an increase in cortisol whereas others do not. Such circumstances have been shown to be the case in previous studies (33). Due to the relatively small size of the present sample, it was not possible to explore this issue any further.

The main finding from the analyses of the heart rate and blood pressure data is that the overtime condition did not show any elevated effects on any of the measurements of ambulatory blood pressure during work, after work, or during sleep. This finding contrasts with the findings of Hayashi et al (4), who demonstrated that a period of intense overtime work was associated with elevated blood pressure and heart rate. However, in the study of Hayashi et al, it was unclear how many hours of overtime were worked on the days when the measurements of ambulatory blood pressure were made. Therefore comparisons between studies are difficult, but stress was clearly present. In our present study, the significant interactions between condition and weekday indicated that blood pressure during work was higher at the beginning of the week in the overtime condition, whereas the opposite pattern was shown for the 8-hour week. There were no such effects with respect to workload, workpace, or stress ratings. One possible expla- nation for this interaction may be that the values on Monday of the overtime condition reflected apprehension of the person in question at the prospect of working a whole week with 12-hour shifts. The elevated levels on Thursday in the 8-hour condition could reflect a greater need to get things done before the week is over. However, we have no other data to support these speculations, and the significant effects shown in the blood pressure and heart rate data are rather weak and should be interpreted with caution. Moreover, the lack of information about posture, physical activity, and emotional state in connection with the blood pressure recordings makes interpretations of these data ambiguous. It is hard to differentiate an effect of physical activity from that of psychosocial stressors. However, we assume that, during work and sleep, the participants' physical activity levels were somewhat constrained and thus remained relatively constant, whereas activity after work was more likely to vary from day to day. Thus one interpretation of the interaction in the analysis of heart rate after work may be that it is simply due to different levels of physical activation.

Previous research has shown that overtime work is associated with increased conflicts between work and family life (34). Our study showed that the participants cut down on time spent on household work, time for themselves, and time socializing with others. However, there were some limitations in the generalizations of these results due to the characteristics of the present study group. There were only four participants that had children, and none had children under 7 years of age. One could expect that people with small children and greater family responsibilities would find it harder to cut down on household work. They might instead be tempted to cut down on sleep.

The data indicate that the effects of the overtime week did not extend into the weekend. This finding can be compared with that of a similar study of a week of high stress and workload, with a natural occurrence of overtime work (average workday 9 hours and 23 minutes), which showed how negative effects on stress and stress or restlessness at bedtime and sleep duration continued into the following weekend (35). This comparison suggests that moderate overtime work in combination with work-related stress has more negative effects on recuperation during weekends than extreme overtime work in the absence of elevated workload. However, apart from the sleep ratings, the data loss in the current study was large for the weekends, and, therefore, there is a risk that we were unable to detect some effects (ie, risk of a type II error).

The current study lacked objective measures of workload or the amount of work carried out by the participants. We instead measured the participants' perception of workload and workpace. Since there were no 
differences in the ratings of these two, we assumed that the work demands experienced by the participants did not differ. Hence we achieved our objective of controlling for what in previous studies has been a confounder (ie, overtime work has been associated with increased work demands). However, objective measures of workload and work performance would have made it possible to ensure that the subjective ratings were valid.

Our present study suffers from some limitations that may diminish the effects of the overtime week. Since the participants could choose which weeks to participate, it is feasible that they selected weeks with no major commitments during their free time. In addition, the participants had only moderate family responsibilities. Furthermore, there is a possibility that some effects of fatigue were masked by the increase in coffee consumption. Fatigue symptoms might have been greater in the overtime week if coffee intake had been held constant between the conditions. Any of these effects could have confounded the comparison between conditions. Thus our results may constitute underestimations.

When interpreting these results, one should bear in mind that the perceived workload was relatively moderate in both conditions and that we do not know what the effects would have been in a more demanding work situation. If how the effects of overtime work are related to work demands is to be fully understood, it would be preferable to manipulate both workhours and workload. In a previous study (35), we manipulated the level of workload and stress, whereas the present study involved the manipulation of workhours. In the previous study there was a natural occurrence of moderate overtime work, and the results showed negative effects on sleepiness, sleep, stress, and physiological stress markers. Similar effects have been shown in other studies of overtime work, whereas our present study failed to show negative effects on stress-related variables. If it is the demanding work situation per se that gives rise to negative effects, it may not be enough to limit the amount of overtime work or length of workhours in order to promote health. Instead it may be more fruitful to focus on the workhours in combination with the work situation. However, the results of our study imply that long workhours alone are associated with negative effects on variables related to fatigue and recuperation. These negative effects may diminish people's abilities to cope with a more stressful work situation.

In conclusion, the results indicate that working overtime when having a rather low workload has a modest effect on the physiological markers of arousal. Greater effects were found on sleep and fatigue, with greater problems during overtime work. However, it should be borne in mind that these findings reflect only one week of exposure, and we cannot know what the long-term effects would have been. Nevertheless, these results are a step in the exploration of the relationship between workhours, workload, and stress. More research is needed to understand fully how workhours interact with other factors, such as work characteristics, workload, stress, and life outside of work. Such research is of great importance in order to help employers optimize workhours with regard to their impact on workers' health and safety.

\section{Acknowledgments}

The study was supported by FAS (The Swedish Council for Working life and Social Science Research).

\section{References}

1. Boisard P, Cartron D, Gollac M, Valeyre A. Time and work: duration of work. Dublin: European Foundation for the Improvement of Living and Working Conditions; 2002.

2. The Swedish Work Environment Authority, Statistics Sweden. The work environment survey 2003. Solna \& Örebro (Sweden): The Swedish Work Environment Authority, Statistics Sweden; 2004.

3. Rissler A, Elgerot A. Stress reaction during overtime work. Stockholm: Department of Psychology, Stockholm University; 1978. Report 23.

4. Hayashi T, Kobayashi Y, Yamaoka K, Yano E. Effect of overtime work on 24-hour ambulatory blood pressure. J Occup Environ Med. 1996;38(10):1007-11.

5. Sokejima S, Kagamimori S. Working hours as a risk factor for acute myocardial infarction in Japan: case-control study. BMJ. 1998;317:775-80.

6. Liu Y, Tanaka H. Overtime work, insufficient sleep, and risk of non-fatal acute myocardial infarction in Japanese men. Occup Environ Med. 2002;59:447-51.

7. Kawakami N, Araki S, Takatsuka N, Shimizu H, Ishibashi H. Overtime, psychosocial working conditions, and occurrence of non-insulin dependent diabetes mellitus in Japanese men. J Epidemiol Community Health. 1999;53(6):359-63.

8. Nakamura K, Shimai S, Kikuchi S, Takahashi H, Tanaka M, Nakano $\mathrm{S}$, et al. Increases in body mass index and waist circumference as outcomes of working overtime. Occup Med. 1998;48:169-73.

9. Shields M. Long working hours and health. Health Report. 1999;11:37-55.

10. Nakanishi N, Nishina K, Yoshida H, Matsuo Y, Nagano K, Nakamura K, et al. Hours of work and the risk of developing impaired fasting glucose or type 2 diabetes mellitus in Japanese male office workers. Occup Environ Med. 2001;58:56974.

11. Nakanishi N, Yoshida H, Nagano K, Kawashimo H, Nakamura K, Tatara K. Long working hours and risk for hypertension in Japanese male white collar workers. J Epidemiol Community Health. 2001;55(5):316-22.

12. Tucker P, Rutherford C. Moderators of the relationship between long work hours and health. J Occup Health Psychol. 2005;10(4):465-76. 
13. Voss M, Floderus B, Diderichsen F. Physical, psychosocial, and organisational factors relative to sickness absence: a study based on Sweden Post. Occup Environ Med. 2001;58(3):17884.

14. Kirschbaum C, Hellhammer DH. Salivary cortisol in psychobiological research: an overview. Neuropsychobiology. 1989;22:150-69.

15. Persson R, Ørbæk P, Ursin H, Kecklund G, Österberg K, Åkerstedt T. Effects of the implementation of an 84-hour workweek on neurobehavioral test performance and cortisol responsiveness during testing. Scand J Work Environ Health. 2003;29:261-9.

16. Steptoe A, Wardle J, Lipsey Z, Mills R, Oliver G, Jarvis M, et al. A longitudinal study of workload and variations in psychological well-being, cortisol, smoking, and alcohol consumption. Ann Behav Med. 1998;20:84-91.

17. Kageyama T, Nishikido N, Kobayashi T, Kawagoe H. Estimated sleep debt and work stress in Japanese white-collar workers. Psychiatry Clin Neurosci. 2001;55(3):217-9.

18. Maruyama S, Morimoto K. Effects of long workhours on lifestyle, stress and quality of life among intermediate Japanese managers. Scand J Work Environ Health. 1996;22:353-9.

19. Proctor SP, White RF, Robins TG, Echeverria D, Rocskay AZ. Effect of overtime work on cognitive function in automotive workers. Scand J Work Environ Health. 1996;22:124-32.

20. Dembe AE, Erickson JB, Delbos RG, Banks SM. The impact of overtime and long work hours on occupational injuries and illnesses: new evidence from the United States. Occup Environ Med. 2005;62(9):588-97.

21. Kecklund G, Ekstedt M, Åkerstedt T, Dahlgren A, Samuelson B. The effects of double-shifts (15.5 hours) on sleep, fatigue and health. Hum Ergol. 2001;30:53-58.

22. Beckers DG, van der Linden D, Smulders PG, Kompier MA, van Veldhoven MJ, van Yperen NW. Working overtime hours: relations with fatigue, work motivation, and the quality of work. J Occup Environ Med. 2004;46(12):1282-9.

23. Åkerstedt T, Knutsson A, Westerholm P, Theorell T, Alfredsson L, Kecklund G. Mental fatigue, work and sleep. J Psychosom Res. 2004;57(5):427-33.

24. Kjellberg A, Iwanowski S. Stress/energi-formuläret: utveckling av en metod för skattning av sinnesstämning $\mathrm{i}$ arbetet: undersökningsrapport [The stress/energy questionnaire: de- velopment of methods for rating mood at work]. Stockholm: Arbetsmiljöinstitutet; 1989. Report no 26.

25. Kjellberg A, Wadman C. Subjektiv stress och dess samband med psykosociala arbetsförhållanden och hälsobesvär: en prövning av Stress-Energi modellen [Subjective stress and its relation to psychosocial work conditions and health complaints: a test of the Stress-Energy model]. Stockholm: Arbetslivsinstitutet; 2002. Arbete och hälsa 12.

26. Åkerstedt T, Gillberg M. Subjective and objective sleepiness in the active individual. Int Neurosci. 1990;52:29-37.

27. Söderström M, Ingre M, Kecklund G, Åkerstedt T, Kecklund L. Lokförarens arbetsbelastning_-påverkan på sömn, trötthet och prestation [Train drivers workload-effects on sleep, fatigue and performance]. Stockholm: Institutet för Psykosocial Medicin (IPM); 2001.

28. Åkerstedt T, Hume K, Minors D, Waterhouse J. The subjective meaning of good sleep, an intraindividual approach using the Karolinska Sleep Diary. Percept Mot Skills. 1994;79:28796.

29. Sadeh A, Hauri PJ, Kripke DF, Lavie P. The role of actigraphy in the evaluation of sleep disorders. Sleep. 1995; 18(4):288-302.

30. Spiegel K, Leproult R, Van Cauter E. Impact of sleep debt on metabolic and endocrine function. Lancet. 1999;354:1435-9.

31. Åkerstedt T, Knutsson A, Westerholm P, Theorell T, Alfredsson L, Kecklund G. Sleep disturbances, work stress and work hours: a cross-sectional study. Psychosom Res. 2002;53:7418.

32. Ekstedt M, Åkerstedt T, Söderström M. Microarousals during sleep are associated with increased levels of lipids, cortisol, and blood pressure. Psychosom Med. 2004;66:925-31.

33. Dahlgren A, Åkerstedt T, Kecklund G. Individual differences in the diurnal cortisol response to stress. Chronobiol Int. 2004;21:913-22.

34. Jansen NW, Kant I, Kristensen TS, Nijhuis FJ. Antecedents and consequences of work-family conflict: a prospective cohort study. J Occup Environ Med. 2003;45(5):479-91.

35. Dahlgren A, Kecklund G, Åkerstedt T. Different levels of work-related stress and the effects on sleep, fatigue and cortisol. Scand J Work Environ Health. 2005;31(4):277-85.

Received for publication: 18 November 2005 